\title{
The relationship between wellbeing indicators and teacher psychological stress in Eastern Cape public schools in South Africa
}

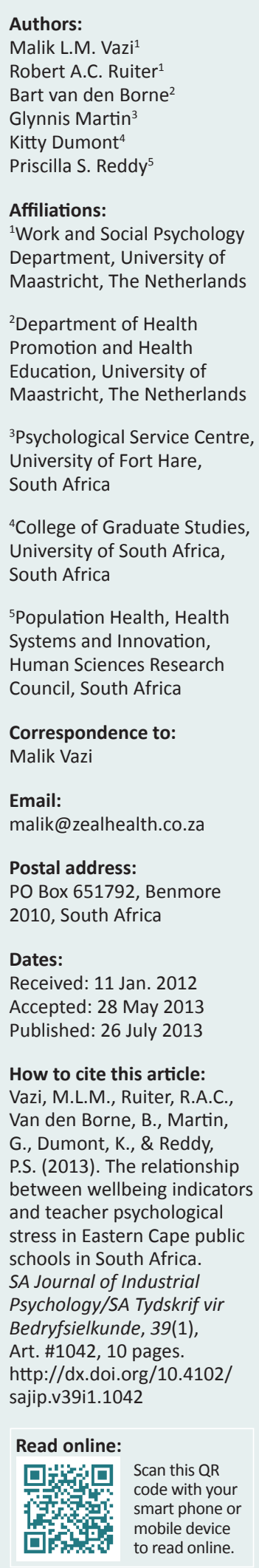

Authors:

Glynnis Martin

Kitty Dumont

Department, University of

Maastricht, The Netherlands

${ }^{2}$ Department of Health

Promotion and Health

Education, University of

${ }^{3}$ Psychological Service Centre,

University of Fort Hare,

University of South Africa,

South Africa

tion,

Human Sciences Research

uncil, South Africa

\section{Correspondence to}

Malik Vazi

\section{Email:}

malik@zealhealth.co.za

PO Box 651792, Benmore

Dates:

Received: 11 Jan. 2012

Accepted: 28 May 2013

Published: 26 July 2013

ow to cite this article:

Vazi, M.L.M., Ruiter, R.A.C.,

G., Dumont, K., \& Reddy,

P.S. (2013). The relationship

tween wellbeing indicator

stress in Eastern Cape public

schools in South Africa.

Art. \#1042, 10 pages.

http://dx.doi.org/10.4102/

sajip.v39i1.1042
Orientation: Positive psychological and subjective wellbeing indicators have proven to be protective against certain physical illnesses but have been rarely assessed in teacher stress.

Research purpose: The main objective of this study was to assess the relationship between indicators of wellbeing and stress and to further assess the relative importance of these wellbeing indicators in explaining stress variance in a large sample of Eastern Cape primary and high school teachers in South Africa.

Motivation for the study: The majority of teacher stress studies focus on the misfit between the individual's resources and the environmental demands. There is a scarcity of studies reporting on protective factors in teaching and we know little about their possible role as possible protective factors against stress. This is important in developing stress prevention strategies.

Research design, approach and method: A cross-sectional survey was used targeting public school teachers in the Eastern Cape. The sample size was 562 randomly selected teachers from both public primary and high schools.

Main findings: The results revealed that stress is prevalent amongst teachers. Subjective and psychological wellbeing factors added significantly to the explained stress variance. Also, both negative affect and role problems had significant positive correlations with stress, whilst psychological wellbeing had a strong inverse relationship with stress.

Practical/managerial implications: The results implied that interventions focusing on improving psychological wellbeing and reduction of negative affect can contribute to stress prevention.

Contribution/value-add: The results contributed towards a better understanding of the relative importance of wellbeing constructs as protective factors against teacher stress.

\section{Introduction}

\section{Problem statement}

\section{Key focus}

The link between poor psychological health and stress in the working population is well documented (Kyriacou \& Sutcliffe, 1978, 1979; Stansfeld, Fuhrer, Head, Ferrie \& Shipley, 1997; Tennant, 2001). Despite several decades of research into its causes, consequences and possible interventions, psychological stress remains a pervasive health and social problem amongst teachers (Dalgard, Mykletum, Rognerud, Johansen \& Zahl, 2007; Fejgin, Ephraty \& Ben-Sira, 1995; Kyriacou \& Sutcliffe, 1978, 1979; Stansfeld et al., 1997; Tennant, 2001). Worldwide, it is well accepted that teaching is a stressful profession. If not mitigated or treated, chronic work stress may result in burnout (Borg \& Riding, 1991; Kyriacou, 1987; Laughlin, 1984; Raschke, Dedrick, Strathe \& Hawkes, 1985). Job dissatisfaction and teacher absenteeism are also commonly cited as negative social outcomes of stress (Bowers, 2001; Hall, Altman, Nkomo, Peltzer \& Zuma, 2005).

Whilst there are various studies reporting on teacher stress in South Africa, comprehensive studies detailing national and provincial prevalence are not readily available. However, there are strong indications that stress is quite prevalent amongst South African teachers and its negative consequences, such as absenteeism, are widely experienced (e.g. Van Bijl \& Oosthuizen, 2007; Hall et al., 2005; Jackson \& Rothmann, 2006). As a developing nation, South Africa needs to continue searching for solutions to the problem of teacher stress; otherwise, teacher absence as a result of psychological problems might increase further. This would reduce available teaching time and consequently learning outcomes. Furthermore, the search for solutions to mitigate against teacher 
stress can no longer be limited to traditional approaches of maladjustment or ill-being, but should also explore factors associated with positive psychological functioning and wellbeing, which can be used as personal resources against stress. This would mean a greater focus on exploring indices or measures of positive functioning such as subjective and psychological wellbeing. These constructs can be assessed for their possible protective value against psychological stress. This approach would not entail replacing one approach with the other, but would involve taking a holistic perspective to teacher stress research.

\section{Background}

The majority of reported teacher stress studies continue to focus on the fit or misfit between the individual's resources and the environmental demands placed on the teacher (see Dalgard et al., 2007; Fejgin et al., 1995; Kyriacou \& Sutcliffe, 1978, 1979; Stansfeld et al., 1997; Tennant, 2001). There is a scarcity of studies on Ryff's (1989a, 1989b) psychological and Diener's (2000) subjective wellbeing factors in the teaching environment and their potential role as protective factors against teacher stress. This is despite psychological and subjective wellbeing factors being reported in other studies as having a health-protecting effect during psychological distress (Abbott et al., 2006). For example, Abbott et al. (2006) reported a positive relationship between psychological wellbeing and mental health. Also, Ryff's (1989a, 1989b) psychological wellbeing has been reported to alleviate burnout symptoms amongst mental health professionals during psychotherapy by Rabin et al. (2011). No studies were found reporting on Ryff's psychological or Diener's (2000) subjective wellbeing as possible protective factors in teacher stress in the Eastern Cape Province of South Africa.

The limited studies reporting on the protective properties of psychological wellbeing justify the present study's interest in the potential value of both subjective and psychological wellbeing constructs in teacher stress prevention. The psychological wellbeing constructs of interest are the multidimensional constructs identified by Ryff (1989a, 1989b), whilst the subjective wellbeing constructs considered in the present study are life satisfaction, positive affect and negative affect, as suggested by Diener (2000).

\section{Objectives}

The main objectives of this study were to assess the relationship between indicators of wellbeing and teacher psychological stress and to further assess the relative importance of these wellbeing indicators in explaining psychological stress variance in a large sample of Eastern Cape primary and high school teachers in South Africa. More specifically, we aimed to assess the relationship between psychological and subjective wellbeing measures, on the one side, and teacher psychological stress, on the other, and to further assess whether adding subjective and psychological wellbeing into the person-environment fit variables contributes to explaining teacher psychological stress variance.

\section{Literature review}

\section{Person-environment fit approach to teacher stress}

Stress is generally conceptualised in terms of the personenvironment fit stress theories by French, Caplan and Harrison (1982), the transactional theory of stress and coping by Lazarus and Folkman (1984) and Karesek's (1979) job demand versus job control model. These theories conceptualise stress as a by-product of an imbalance between job or environmental demands, on the one hand, and the ability to meet these demands on the other, mitigated by a person's job control and decision latitude. The identified stress theories report on various environmental or job factors as potential stressors and a limited number of changeable personal factors that could make the teacher more or less able to cope with the environmental factors (see Borg \& Riding, 1991; Caplan, 1987; Chaplain, 1995; Dalgard et al., 2007; French et al., 1982; Kyriacou \& Sutcliffe, 1978, 1979; Harrison, 1985; Laughlin, 1984; Manthei \& Gilmore, 1996; Raschke et al., 1985; Stansfeld et al., 1997; Tennant, 2001). Amongst teachers, however, stress is generally accepted as an occupational reality that comes with the profession. Typically, stress is believed to be more prevalent in professions where individuals work with other people, such as in teaching, policing, health services and counselling work environments (see Kyriacou, 1987; Jackson \& Rothmann, 2006; Santavirta, Soloviena \& Theorel, 2007; Tennant, 2001; Van Bijl \& Oosthuizen, 2007).

The most common framework used to understand factors involved in the stress process or transaction is the stress and coping theory of Lazarus and Folkman (1984). This theory suggests that stress is a two-way process: the environment produces stressors and the individual finds ways to deal with these stressors. It further suggests that people cognitively appraise stressors according to primary and secondary appraisals. During primary appraisal, the individual is seeking the meaning of the situation with regard to their wellbeing, whilst secondary appraisal includes feelings of not being able to deal with the problem. This implies that individual differences on stress appraisal can be expected amongst teachers who experience similar stressful events or environmental demands. This is probably the main reason why some teachers develop stress symptoms and others do not whilst working in the same environment and facing the same challenges. Therefore, any effort to gain a better understanding of what makes some succumb to stress whilst others show resilience should be encouraged.

The majority of stress studies commonly discuss environmental predictors of stress and a limited number of personal characteristics that potentially mediate stress. For instance, environmental factors that are commonly reported include lack of time and workload pressures (Borg \& Riding, 1991; Laughlin, 1984), disruptive student behaviour and student problems (Borg \& Riding, 1991; Chaplain, 1995) and problems with school administration and staff (Borg \& Riding, 1991; Smith \& Bourke, 1992). Student behaviour problems have generally been identified as the greatest source of stress and burnout for both primary and secondary teachers (Borg \& 
Riding, 1991; Chaplain, 1995; Laughlin, 1984; Raschke et al., 1985). Personal factors commonly reported as predictors of stress in teachers are low self-esteem, external locus of control and low teacher efficacy (Byrne, 1999; Fejgin et al., 1995; Kyriacou \& Sutcliffe, 1978, 1979).

Teacher efficacy has been defined as a teacher's judgement of his or her capabilities to bring about desired outcomes of student engagement and learning, even amongst those students who may be difficult or unmotivated (TschannenMoran, Woolfolk Hoy \& Hoy, 1998). It is closely related to self-efficacy, which is defined by Bandura (1997) as a personal belief in the personal ability to organise and execute course of action.

External locus of control is the perception of an individual that he or she does not have control of his or her life or behaviour and is, therefore, excluded from the decisionmaking processes that affect him or her (Dorman, 2003). It is also the extent to which a teacher has a generalised expectancy of external rather than internal control over reinforcement. External locus of control has been positively associated with teacher stress (Dorman, 2003). High teacher efficacy, internal locus of control and a healthy self-esteem are reported to be negatively related to stress and burnout in teachers (Dorman, 2003).

Similar studies in South Africa indicate that local teachers face similar challenges at schools. For instance, in a study on educator attrition, Hall et al. (2005) reported that South African teachers, including those from the Eastern Cape, complained about increased work pressure, job overload and reduced job satisfaction, which are regarded as key correlates of teacher stress. Also, in a previous study on determinants of burnout amongst Eastern Cape teachers, we reported that work pressure, role problems, such as lack of role clarity, and the presence of role conflict and ambiguity were associated with high levels of burnout feelings, especially the dimension of emotional exhaustion, which is closely related to stress (Vazi et al., 2011).

Whilst teacher stress research generally focuses on the work domain, it is impossible to ignore the role of the private domain in the stress-stressor process. These two domains can 'reinforce' each other and/or 'sabotage' each other. There are a number of studies that have reported on the positive influence of family support on the work domain (Grandey \& Cropanzano, 1999; Hobfoll, Freedy, Schaufeli, Maslach \& Marek, 1993). These studies suggest that work demands placed on an individual might conflict with family demands. An example could be the requirement on teachers to teach extra classes after hours or during weekends. This work demand might be in conflict with family needs such as making time for loved ones. Also, lack of balance between work and family domains can result in spill-over effect, whereby a teacher's worries about family problems, such as divorce or sick children, can lower a teacher's stress resilience threshold at work. This is explained as depletion of coping resources in the conservation of resources theory (Hobfoll et al., 1993). This theory suggests that people strive to protect and build resources, for example objects such as money, conditions such as access to quality social support, energies and personal characteristics such as beliefs. It further argues that psychological stress occurs when these resources are lost or threatened (Hobfoll et al., 1993).

\section{Wellbeing approach to understanding teacher stress}

Literature on wellbeing can be categorised into two related perspectives, namely 'subjective wellbeing', which is associated with the hedonic approach, and 'psychological wellbeing', which is associated with the eudaimonic approach. Negative affect, a component of low subjective wellbeing, has been argued by Yu (2009) as both a stress outcome and a possible stress input. This suggests that negative affect can exist prior to the development of stress, or serve as an indicator of illbeing. Furthermore, Salami (2010) reported on negative affect as a moderator between teacher stress and counterproductive work behaviours such as absenteeism.

In a previous study on burnout amongst teachers from the Eastern Cape Province, we also reported a significant positive correlation between negative affect and the burnout dimensions of emotional exhaustion and depersonalisation (Vazi et al., 2011). Whilst burnout and stress are different, they are closely related and generally linked to the same work-based psychosocial factors (Pines \& Keinan, 2005). It is therefore possible that wellbeing constructs such as psychological wellbeing and subjective wellbeing can be more than mere outcomes of person-environment misfit.

More generally, subjective wellbeing is defined in terms of affect and cognitive evaluations of life satisfaction (Diener, 2000; Diener, Suh, Lucas \& Smith, 1999). According to this theory, a teacher will experience subjective wellbeing if there are experiences or overall feelings of life satisfaction, satisfaction with other relevant domains, such as work, and more positive emotions and moods than negative ones in the course of daily living. Fredrickson (1998), in her broaden and build theory of emotions, has argued that positive affect is associated with improved problem solving and creativity in dealing with situations. This creativity and improved problem-solving abilities are compatible with better coping behaviours. It is therefore reasonable to argue that a teacher who scores high on positive affect and life satisfaction and scores low on negative affect will probably appraise stressors as less threatening when compared to a teacher with opposite scores. Appraisal of stressors as less threatening is a recognised coping mechanism and it benefits mental health (Lazarus \& Folkman, 1984). Incidentally, in the mental health continuum by Keyes and Lopez (2002), life satisfaction, presence of positive affect and absence of negative affect are altogether referred to as representative of good emotional wellbeing.

Positive affect has also been linked to flourishing, whilst negative affect has been linked to languishing or mere survival (Fredrickson \& Losada, 2005). According to Fredrickson and Losada (2005), to flourish means to live with an optimal range of human functioning, one that connotes goodness, 
growth and resilience. Keyes (2002) argues that people can move from languishing to flourishing and function well if they develop positive emotional wellbeing, positive social wellbeing and positive psychological wellbeing. To be fully functional and flourishing, an individual needs positive social evaluation in addition to personal appraisal of subjective and psychological wellbeing (Keyes, 2002). The social dimensions that constitute social wellbeing are social coherence, social integration, social contribution, social actualisation and social acceptance. The mental health continuum proposed by Keyes (2002) summarises social wellbeing as follows:

Individuals are functioning well when they see society as meaningful and understandable, when they see society as possessing potential for growth, when they feel they belong to and are accepted by their communities, when they accept most parts of society, and when they see themselves contributing to society. (pp. 207-222)

These five dimensions of social wellbeing are comparable to Ryff's (1989a, 1989b) six dimensions of psychological wellbeing, namely, self acceptance, autonomy, positive relations with others, environmental mastery and personal growth, which are the focus of the present study.

Psychological wellbeing has been defined by Ryff (1989a, $1989 b$ ) as a multidimensional construct that comprises various social, psychological and physiological aspects, which may be interrelated and which may influence each other. These dimensions are: personal growth, autonomy, environmental mastery, self-acceptance, purpose in life and personal relations. 'Personal growth' relates to being open to new experiences as well as having the continued ability to develop and expand as a person. 'Autonomy' refers to peoples' sense of self-determination, independence and freedom from norms. 'Environmental mastery' means a person's ability to manage life and his or her surroundings. 'Self-acceptance' is defined as a positive attitude towards oneself and one's past life experiences. 'Purpose in life' is when a person has life goals and the belief that their life is meaningful. 'Personal relations' refer to high quality, satisfying relationships with others (Ryff, 1989a, 1989b). All these psychological wellbeing constructs reflect a great degree of access to coping resources, such as skills and supportive personal relations, which are proven to be important in coping with psychological stress. This further suggests that a teacher with high scores on psychological measures will probably appraise stressors as less threatening compared to a teacher with low scores.

The potential benefit of using wellbeing constructs as protective factors, has not been fully explored in relation to teacher stress as it has in other contexts. For instance, Abbott et al. (2006) reported a positive relationship between high levels of psychological wellbeing and good mental health. Also, in a meta-analysis of prospective studies on positive psychological wellbeing and mortality, Chida and Steptoe (2008) reported a positive correlation between psychological wellbeing and the health status of cardiovascular patients, as well as a reduced death rate in patients with renal failure and with HIV infection amongst those that reported more positive scores on indices of psychological wellbeing. In a previous study on teacher burnout, we also reported a significant inverse relationship between a psychological wellbeing measure and the burnout dimensions of emotional exhaustion and depersonalisation (Vazi et al., 2011).

The following hypotheses are submitted as integral in pursuing the stated objectives of this study:

- Hypothesis 1: positive affect, life satisfaction and psychological wellbeing will be negatively correlated to stress.

- Hypothesis 2: negative affect will be positively correlated to stress.

- Hypothesis 3: the inclusion of psychological wellbeing and subjective wellbeing factors will contribute to explaining stress variance.

Confirmation of these hypotheses could lead to the inclusion of these factors in promoting or enhancing coping behaviours in teachers. To policymakers, managers and employee wellness practitioners, that would constitute another strategy in stress prevention and the promotion of psychological health amongst teachers.

\section{Research design Research approach}

A quantitative, cross-sectional survey was conducted to assess the relationship between indicators of wellbeing and teacher psychological stress and to further assess the relative importance of these wellbeing indicators in explaining psychological stress variance in a large sample of Eastern Cape primary and high school teachers in South Africa.

\section{Research method}

\section{Participants and sampling procedure}

The data for this report were drawn from a larger study conducted in 2008 on health and wellness needs amongst teachers and supporting employees of the Department of Education in the Eastern Cape Province, South Africa. Teachers at primary and high schools were selected for this specific study. The Eastern Cape Province is the second largest province in South Africa, comprising $168966 \mathrm{~km}^{2}$, and borders the Indian Ocean. The estimated population is 6527 747 people and the main inhabitants are isiXhosa speakers (83.4\%) of the Nguni tribe (Statistic South Africa, 2009). The total number of teachers in the province is estimated to be 62 000, of which about 72\% are women (Eastern Cape Department of Education officials, personal communication, April, 2008).

The study participants were primary and high school teachers originating from both the rural and urban areas of the province. The provincial Department of Education drew up a list of 15808 permanent public service and college or school educators, including details of name, gender, age, school, occupation and contact address from the payroll system, which was used as the sample frame. The sample frame was organised according to the 23 school districts which were grouped into large, medium and small district 
categories, in addition to being classified as either urban or rural. The 1300 participants (868 teachers and 423 nonteachers) were randomly sampled with replacement from nine districts within these clusters. The present study only included teachers. Also, race was not an inclusion criterion, whilst being a fulltime teacher in the Eastern Cape was.

\section{Assessment instrument}

The self-report questionnaire included previously validated scales to assess stress, personality characteristics, environmental stressors and subjective and psychological wellbeing variables. Likert scales with five response options, ranging from $1=$ strongly agree to $5=$ strongly disagree, were used. In some cases, shorter versions of scales were used to reduce fillingout time and to increase response and completion rates. All scales were checked for internal consistency and averaged into one single index (unless otherwise indicated). Scores were recoded such that higher scores reflected a stronger presence of the variable concerned.

Work stress symptoms: Work stress symptoms were assessed by applying the work stress symptoms scale developed by Bjökquist and Österman (1992). The scale consists of 10 different symptoms (such as irritation and depression) and the employees were asked to indicate whether, and to what degree, they had suffered from these symptoms in the last twelve months. The scale revealed an acceptable internal consistency $(\alpha=0.90)$.

Teacher efficiency: This is the extent to which teachers believe that they are contributing significantly to the academic progress of their students and can effectively teach all students, as well as teachers' beliefs that they are capable, significant, successful and worthy (Dorman, 2003). The study initially tried to measure teacher self-efficacy and teacher self-esteem separately, using two subscales with three items from scales reported in Dorman (2003). Internal consistency measures were, however, poor and a decision was made to combine the two scales and create a new variable labelled teacher efficacy with four items $(\alpha=0.69)$. The four items were: 'I contribute significantly to the academic progress of my students', 'I am confident to use different teaching methods', 'I feel good in my job as a teacher' and 'People usually follow my ideas'.

External locus of control: This is the extent to which a teacher has a generalised expectancy rather than internal control over reinforcement (Dorman, 2003). We used a scale consisting of three items, similar to one used by Dorman (2003), and adapted Rotter's (1966) locus of control scale to measure locus of control $(\alpha=0.63)$. The items were: 'Decisions related to the school are made without me', 'I feel that I have little influence over the school events that happen to $\mathrm{me}^{\prime}$ and 'My influence over school related decisions is limited'.

Role problems: Here, the focus is on the extent to which clear information about the role required of teachers is absent and two or more work demands are incompatible (Dorman, 2003). Typically, role ambiguity, role conflict and role overload are measured independently (Dorman, 2003); however, as a result of low internal consistency, a new scale with four items from the 'role ambiguity' and 'conflict' subscales, called 'role problems', was created to improve internal consistency. The role problem items $(\alpha=0.68)$ were: 'I never know what I will have to deal with at school tomorrow', 'I can predict what will be expected of me at school tomorrow', 'It is difficult to satisfy the conflicting demand of students, parents and administration' and 'I feel that I can never satisfy all people involved in a conflict'.

Work pressure: This is the extent to which teachers experience work pressure (Dorman, 2003). High work pressure is reported in the literature as having a positive correlation with teacher stress and burnout (Dorman, 2003). In this study, it was measured by two items $(\mathrm{r}=0.54)$, namely, 'Teachers at my school have to work long hours to complete all their work' and 'Teachers at my school have to teach too many hours'.

Positive work environment: This is the extent to which teachers experience a high-quality school and classroom psychological environment (Dorman, 2003). Nine items out of eleven from subscales used for school and classroom environment measurement in Dorman (2003) were combined into one measure of positive work environment because of overlapping and poor consistency in the subscales. Examples of items used are: 'The climate at my school is characterised by friendliness and discipline', 'The class always starts on time at my school' and 'Access and security is well managed at my school'. The new scale showed acceptable internal consistency $(\alpha=0.78)$.

Subjective wellbeing: The satisfaction with life scale developed by Diener (1985) was used to assess life satisfaction with five items (e.g. 'In most ways my life is close to my ideal', 'The conditions of my life are excellent', 'I am satisfied with life'; $\alpha=0.80$ ). Positive affect and negative affect were each measured using 12 items from the positive affect negative affect scale (Watson, Clark \& Tellegen, 1988; also cited in Dorman, 2003). Reliability was $\alpha=0.85$ for positive affect (items used included words such as 'cheerful', 'enjoyed things', 'happy') and $\alpha=0.80$ for negative affect (items used included 'tense', 'afraid' and 'worried').

Psychological wellbeing: The present study used 24 items from the shortened version of Ryff's (1989a, 1989b) psychological wellbeing scale. These items sought to measure the six dimensions of personal growth, autonomy, environmental mastery, self-acceptance, purpose in life and personal relations. To test the proposed six-factor structure, a principal component analysis with varimax rotation was computed. Three factors were extracted, each with an eigenvalue greater than 1 and these factors related to positive self-evaluation, self of contentment and sense of competence. This structure differed from the predicted six-dimensional structure reported in Ryff's (1989a, 1989b) psychological wellbeing scale. Given that the aim of this study was not to test the validity of the six dimensions but to obtain an overall measure of a teacher's sense of psychological wellbeing, it 
was decided to compute an overall psychological wellbeing score. The combined psychological wellbeing scale had 28 items, after excluding two items referring to the dimensions of autonomy ('it is difficult for me to voice my opinions on controversial matters') and self-acceptance ('my attitude about myself is probably not as positive as most people feel about themselves') revealed a satisfactory internal consistency with $\alpha=0.76$.

\section{Research procedure}

Study design and procedure: The cross-sectional survey was undertaken in 2008. Interviewers were selected from the staff of the Integrated Employee Wellness Unit of the Eastern Cape Department of Education. The interviewers were selected by the Department of Education according to guidelines given to the department by the project team. The guidelines included the ability to fluently read and write English and isiXhosa and having access to transport. Preference was to be given to those with previous experience in community research and/ or had a degree in Social Sciences.

The questionnaire was pre-tested and was adapted based on feedback. The interviewers received in-depth training on questionnaire administrative procedures. Using the employee contact details provided by the Department of Education, telephonic appointments were made with the participants. Interviewers obtained informed consent from participants, and explained that the survey was both confidential and voluntary. The questionnaires were administered either individually or in groups within the school setting. Where participants were given the questionnaires as part of a group, they were seated separately from each other to avoid collusion. Data from the completed questionnaires were captured, cleaned and prepared for analysis.

\section{Statistical analysis}

The software package SPSS version 17.0 (2008) was used for data analysis. Frequencies were conducted for demographic and descriptive variables. Bivariate correlations were calculated for the psychosocial variables and teacher stress. Hierarchical multiple regression analysis was conducted to explore the unique contribution of each variable in explaining teacher stress. Variables that showed significant bivariate correlations with teacher stress were added to the model stepwise. The enter method was used for this purpose, allowing all predictors to be entered simultaneously at each step. A significance level of $5 \%$ was used throughout.

The first set of variables entered were those from personenvironment theories, namely positive environment, work pressure, external locus of control, teaching efficacy (newly created combination of teacher efficacy and self-esteem) and role problems (role conflict and ambiguity). This analysis is referred to as Model 1 in this article.

The second set of variables added were subjective wellbeing variables, reflected as life satisfaction, positive affect and negative affect. This is referred to as Model 2 in this article. The third and last entry was the addition of variables representing psychological wellbeing and this was measured and entered as a psychological wellbeing index. This last entry is referred to as Model 3 and was the most expansive of the three models.

\section{Results}

From a sample of 868 teachers, 610 agreed to participate in the survey. However, only 562 questionnaires were considered valid and included in the survey. Twenty-two questionnaires were excluded because they were completed with the assistance of a research team member and 26 had missing information. All the participants were Black African, of which 395 were women and 144 were men. This was despite the fact that race was not used as a criterion for inclusion in the study. Twenty-three participants did not indicate their gender. The mean age was 43.5 years old, with the minimum being 24 years and maximum 65 years.

Means, standard deviations (SD) and correlation coefficients are reported in Table 1 . The average score on the measure of teacher stress was $M=2.56$ (SD = 0.97). However, $31 \%$ of the teachers had a stress mean score greater than three, an indication of high stress experience. The results of intercorrelations were as anticipated from the literature, with few exceptions. For instance, of the person-environment fit

TABLE 1: Correlates of work stress.

\begin{tabular}{|c|c|c|c|c|c|c|c|c|c|c|}
\hline Work stress variables & $\begin{array}{l}\text { Psychological } \\
\text { wellbeing }\end{array}$ & $\begin{array}{l}\text { Role } \\
\text { problems }\end{array}$ & $\begin{array}{l}\text { Positive } \\
\text { environment }\end{array}$ & $\begin{array}{l}\text { Teaching } \\
\text { efficiency }\end{array}$ & $\begin{array}{l}\text { External } \\
\text { locus of } \\
\text { control }\end{array}$ & $\begin{array}{l}\text { Work } \\
\text { pressure }\end{array}$ & $\begin{array}{l}\text { Work stress } \\
\text { symptom } \\
\text { scale }\end{array}$ & $\begin{array}{l}\text { Life } \\
\text { satisfaction }\end{array}$ & $\begin{array}{l}\text { Negative } \\
\text { affect scale }\end{array}$ & $\begin{array}{l}\text { Positive } \\
\text { affect scale }\end{array}$ \\
\hline Psychological wellbeing & 1 & - & - & - & - & - & - & - & - & - \\
\hline Role problems & $-0.42 * *$ & 1 & - & - & - & - & - & - & - & - \\
\hline Positive environment & $-0.13^{* *}$ & $0.10^{*}$ & 1 & - & - & - & - & - & - & - \\
\hline Teaching efficiency & 0.05 & $0.08^{*}$ & $0.59 * *$ & 1 & - & - & - & - & - & - \\
\hline External locus of control & $-0.40 * *$ & $0.59 * *$ & $0.20 * *$ & $0.17^{* *}$ & 1 & - & - & - & - & - \\
\hline Work stress symptom scale & $-0.48 * *$ & $0.49 * *$ & 0.01 & -0.03 & $0.39 * *$ & $0.13^{* *}$ & 1 & - & - & - \\
\hline Life satisfaction & -0.02 & $0.20 * *$ & $0.43^{*} *$ & $0.42^{* *}$ & $0.21 * *$ & $0.07 *$ & 0.05 & 1 & - & - \\
\hline Negative affect fect Se Ascale & $-0.35 * *$ & $0.38^{* *}$ & 0.03 & $0.08^{*}$ & $0.36^{* *}$ & $0.07 *$ & $0.50 * *$ & $0.09 *$ & 1 & - \\
\hline Positive affect scale & $0.10^{* *}$ & 0.07 & $0.41 * *$ & $0.44^{* *}$ & $0.12^{* *}$ & 0.06 & $-0.09 *$ & $0.56^{* *}$ & -0.05 & 1 \\
\hline Mean & 3.53 & 2.74 & 3.32 & 3.71 & 2.84 & 3.44 & 2.56 & 3.23 & 2.62 & 3.49 \\
\hline Standard deviation & 0.43 & 0.89 & 0.70 & 0.65 & 0.92 & 0.97 & 0.97 & 0.95 & 0.90 & 0.81 \\
\hline
\end{tabular}

***, Correlation is significant at the 0.001 level; ${ }^{* *}$, Correlation is significant at the 0.005 level; ${ }^{*}$, Correlation is significant at the 0.05 level. 
stress model, positive correlations with teacher stress were found for role problems $(r=0.490, p<0.01)$, external locus of control $(r=0.213, p<0.01)$ and work pressure $(r=0.125$, $p<0.01)$. Positive work environment measured by good infrastructure, supportive school and class environments, showed no correlation with stress, whilst we expected an inverse relationship.

For the measures of subjective wellbeing, life satisfaction did not show a significant correlation with teacher stress, whilst negative affect was positively correlated $(r=0.502)$. Psychological wellbeing showed a negative correlation with teacher stress $(r=-0.476, p<0.01)$.

Hierarchical multiple regression was conducted on all three models. The analysis of Model 1 showed the contribution of person-environment fit to explaining reported teacher stress. The analysis of Model 2 indicated the contribution of subjective wellbeing to reported teacher stress and, finally, the analysis of Model 3 indicated the contribution of psychological wellbeing variables to the explanation of reported teacher stress (Table 2). Variables from these three perspectives were reported in the same expansive manner in which they were added in building the final Model 3. All three models are reported in Table 2.

\section{Person-environment fit}

Model 1 represented a regression analysis of the traditionally reported stress predictors, which were 'positive work environment', 'external locus of control', 'role problems', 'work pressure' and 'teacher efficacy'. These variables explained $26 \%$ of the variance in the measure of teacher stress. Only external locus of control $(\beta=0.18, p<0.001)$ and role problems $(\beta=0.39, p<0.001)$ were significant in predicting psychological stress. Positive work environment and teacher efficiency did not show any significance.

\section{Subjective wellbeing}

Adding subjective wellbeing variables, namely, 'life satisfaction', 'positive affect' and 'negative affect' to variables of Model 1 yielded the results reported in Model 2. Model 2 explained $38 \%$ of the variance in teacher stress, as opposed to
$26 \%$ explained by Model 1. In Model 2, the increase was driven by negative affect $(\beta=0.36, p<0.001)$ as the contribution of external locus of control and role problems were reduced to $\beta=0.09(p<0.050)$ and $\beta=0.29(p<0.001)$, respectively.

\section{Psychological wellbeing}

Model 3, the final model, which contained the additional measure of 'psychological wellbeing', and was therefore the most expanded model, explained $42 \%$ of the variance in teacher stress, as opposed to 38\% explained by Model 2 . Only role problems $(\beta=0.24, p<0.001)$ and negative affect ( $\beta=0.31, p<0.001)$ were carried through into the final model, together with psychological wellbeing $(\beta=0.24$, $p<0.001)$. Positive affect, teacher efficiency, positive work environment, external locus of control and work pressure were not significant predictors of psychological stress in the final model.

\section{Discussion Outline of the results}

This study aimed to assess the relationship between indicators of wellbeing and teachers' experience of psychological stress. Furthermore, the relative importance of these wellbeing indicators in explaining psychological stress variance amongst teachers was evaluated. This study has used factors adapted for different cultural settings whilst remaining grounded in theories of stress and wellbeing.

The results of this study indicate that psychological stress is experienced by $31 \%$ of teachers in the Eastern Cape, who reported experiencing stress symptoms either often or very often. The results confirmed a significant positive correlation between stress and external locus of control. Teacher efficiency had a negative correlation with stress; however, it was not significant. This could mean that when it comes to stress, teachers are more concerned with being excluded from decision-making than their teaching abilities and professional self-esteem, as indexed by teacher efficiency in the study. It is also important to note that teacher efficiency had the highest mean score, suggesting that teachers believe they have high levels of teaching abilities and have high professional self-esteem.

TABLE 2: Hierarchical regression of extended teacher stress model correlates.

\begin{tabular}{|c|c|c|c|c|c|c|c|c|c|}
\hline \multirow[t]{2}{*}{ Variables } & \multicolumn{3}{|c|}{ Model 1} & \multicolumn{3}{|c|}{ Model 2} & \multicolumn{3}{|c|}{ Model 3} \\
\hline & B & SE:B & $\beta$ & B & SE:B & $\beta$ & B & SE:B & $\beta$ \\
\hline Positive work environment & -0.02 & 0.04 & -0.02 & 0.04 & 0.06 & 0.03 & -0.04 & 0.06 & -0.03 \\
\hline External locus of control & 0.19 & 0.05 & $0.18^{* * *}$ & 0.09 & 0.05 & $0.09 *$ & 0.05 & 0.05 & 0.05 \\
\hline Role problems & 0.43 & 0.05 & $0.39 * * *$ & 0.33 & 0.05 & $0.29 * * *$ & 0.27 & 0.05 & $0.24 * * *$ \\
\hline Work pressure & -0.01 & 0.05 & -0.01 & 0.01 & 0.04 & 0.01 & 0.00 & 0.04 & 0.00 \\
\hline Teaching efficiency & -0.13 & 0.07 & -0.09 & -0.13 & 0.07 & $-0.09 *$ & -0.05 & 0.07 & -0.04 \\
\hline Life satisfaction & - & - & - & 0.02 & 0.05 & 0.02 & 0.03 & 0.04 & 0.03 \\
\hline Positive affect & - & - & - & -0.10 & 0.05 & -0.08 & -0.07 & 0.05 & -0.06 \\
\hline Negative affect & - & - & - & 0.39 & 0.04 & $0.36 * * *$ & 0.33 & 0.04 & $0.31 * * *$ \\
\hline Psychological wellbeing & - & - & - & - & - & - & -0.57 & 0.09 & $-0.24 * * *$ \\
\hline $\mathrm{R}$-squared $\left(R^{2}\right)$ & - & 0.26 & - & - & 0.38 & - & - & 0.42 & - \\
\hline R-squared change & - & 0.26 & - & - & 0.11 & - & - & 0.04 & - \\
\hline F-change & - & $38.37^{* * *}$ & - & - & $32.53 * * *$ & - & - & $36.99 * * *$ & - \\
\hline
\end{tabular}

${ }^{* * *}$ Correlation is significant at the 0.001 level; ${ }^{* *}$ Correlation is significant at the 0.005 level; ${ }^{*}$ Correlation is significant at the 0.05 level.

$B$, unstandardised coefficient; SE:B, standard error; $\beta$, standardised coefficient; $R^{2}$, explained stress variance; $F$, test statistic in the model. 
Work pressure and role problems were found to be positively correlated with stress. These findings suggest that personenvironment fit theories (Caplan, 1987; Caplan \& Harrison, 1993; Dorman, 2003; Dalgard et al., 2007; French et al., 1982; Harrison, 1985; Kyracou \& Sutcliffe, 1978, 1979) are applicable to stress in the teaching environment.

The positive correlation between stress and the negative affect component of subjective wellbeing supported the findings of earlier studies (Lazarus, 1993). This could mean that teachers appraise the work environment as threatening and, in turn, develop stress symptoms, which include negative affect. It is also possible that negative affect preceded stress symptoms and therefore was either part of teachers' personalities or was caused independently by events at school. Irrespective of the origin of negative affect in teachers, it is clear that its presence increases the risk of stress symptoms. Also, negative affect reduces creativity and, therefore, the problem-solving capabilities normally associated with effective coping (Fredrickson \& Lasoda, 2005). Negative affect must, therefore, be addressed in future stress management interventions.

Positive affect was found to have a negative correlation with stress, which supported the findings of previous studies such as those of Lazarus (1993) and Fredrickson and Lasoda (2005).

No significant negative correlation between stress and life satisfaction was found. In fact, life satisfaction had a positive but insignificant correlation with stress, suggesting that work stress was not necessarily a major determinant of life satisfaction.

This study indicated a strong inverse relationship between stress and psychological wellbeing. This, however, does not imply causality. The study found that psychological wellbeing has an inverse relationship with the following factors: external locus of control, role problems, work pressure and negative affect. However, psychological wellbeing has a positive correlation with positive affect.

The regression analysis results of Model 1 (and reported in Table 2) indicate that only external locus of control and role problems are significant predictors of teacher stress. These findings suggest that teachers experience role conflict and there is ambiguity around their expected functions. Together with exclusion from teaching-related decision-making, these role problems are viewed as threatening by teachers and they are appraised as stressors, which are directly linked to teacher psychological stress. However, these two factors only explained $29 \%$ of the teacher psychological stress variance. It was theoretically expected that all environmental factors and personal attributes, such as teaching efficiency and external locus of control, would contribute to predicting teacher stress. The contribution made by work environment conditions was not statistically significant and is, therefore, not consistent with the public reports on poor school infrastructure and student misbehaviour in government schools in South Africa, especially in the rural Eastern Cape. These results are also not consistent with findings from other studies, such as those reported by Dorman (2003), which linked a positive school environment with better teacher psychological health or absence of burnout and stress. It is possible that teachers have developed other compensating mechanisms, such as creating psychological distance from the environment, to the extent that lack of school safety, poor infrastructure and student misbehaviour are no longer a priority to them. Another simple explanation could be measurement problems and understandability of items by the respondents. Unlike in Dorman (2003), where more items per subscale were used, we used fewer items, which could have resulted in a less accurate measurement of the work environmental climate. Also, the respondents might not have understood some of the responses, as English is their second language, despite being a well spoken language by these teachers.

Addition of the subjective wellbeing measures of life satisfaction, negative affect and positive affect in Model 2 resulted in the reduction of the contribution by external locus of control and role problems, but made teacher efficiency's contribution significant. This change is somewhat surprising given that only negative affect from the subjective wellbeing dimension was significant in predicting stress, meaning there was no significant contribution by either positive affect or life satisfaction. It can be speculated that despite the insignificant contribution by positive affect and life satisfaction in predicting psychological stress, current levels of positive affect and life satisfaction amongst teachers make external locus of control and role problems less threatening. Also, the presence of positive affect makes teacher efficiency more useful in reinforcing coping behaviours. This is plausible given Fredrickson's (1998) argument that the presence of positive affect enhances creativity and problem solving. Also there is a long-held view in affect literature that negative affect is associated with survival-seeking behaviours and their effect might be stronger than positive affect (Fredrickson \& Lasoda, 2005). This means that to overcome the harm of negative affect and promote health and wellbeing, a much greater proportion of positive affect is needed (Fredrickson \& Lasoda, 2005). The most important finding, however, is that negative affect increased the variance explained from $29 \%$ to $38 \%$ and this indicates the relative importance of negative affect in stress management.

As hypothesised, psychological wellbeing is inversely related to stress and its inclusion in Model 3 increased the proportion of explained variance from $38 \%$ to $42 \%$. In the final model, only role problems, negative affect and psychological wellbeing were significant predictors of stress and the suggested directions of the relationships were as expected. Teachers appear to be stressed by role problems such as role conflict and role ambiguity. These role problems possibly arouse negative affect in these teachers and this further gives rise to psychological stress. Alternatively, role problems result in psychological stress, which then creates a valence of negative affect. The mean scores for positive affect and negative affect indicate that these teachers had more positive affect and less negative affect. This could 
eliminate the possibility that negative affect in this group of teachers is part of their personality and suggest that negative affect is associated with psychosocial factors or stressors at schools. The finding that psychological wellbeing is inversely related to negative affect, role problems and external locus of control provides an opportunity for further screening of psychological wellbeing for possible resilience features that can assist in stress prevention.

Negative affect, a measure of subjective wellbeing, is a significant factor in psychological stress in teachers. This implies that early screening for negative affect can help to identify individuals vulnerable to developing stress. Reducing a teacher's negative affect can help to reduce stress feelings. Salami (2010) reported a positive relationship between negative affect and counterproductive behaviour amongst teachers, which means reducing negative affect can also reduce these counterproductive behaviours.

\section{Practical implications}

The findings could provide data on modifiable wellbeing factors that can be incorporated into future interventions on stress prevention for school teachers. In addition, this information can make a contribution to developing costeffective, evidence-based interventions that are likely to be supported by managers, health promotion planners and implementers.

The study implies that interventions aiming to increase psychological wellbeing, through enhancing environmental mastery, autonomy, positive relations with others, personal growth, life purpose and self-acceptance, would help teachers to cope better with stress. There is more evidence to suggest that a positive change in coping behaviours with positive psychological wellbeing as defined by Ryff (1989a $\& 1989$ b) is clinically sound. For instance, improvements in psychological wellbeing have been linked with coping with traumas of abuse amongst Asian women (Rodriguez, 2011). Also, psychological wellbeing is reported in the various studies described in this research as being inversely related to both outcome variables of stress and burnout. Furthermore, psychological wellbeing is reported in our research, as being inversely related to key determinants of stress and burnout such as role problems, external locus of control, low teacher efficiency and negative affect. This implies that, by targeting one variable, an adverse impact of a number of environmental and personal determinants can be mitigated.

Interventions that address positive affect and psychological wellbeing can provide teachers with the problem-solving abilities and creativity to prevent stress or minimise its impact. Current evidence suggests that a net increase in positive affect is linked to an increase in creativity and problemsolving abilities and therefore better coping (Frederickson \& Losado, 2005). Based on this argument, health promotion planners would be better advised to prioritise qualitative improvements in positive affect, to empower teachers cope with stress and burnout.
Because stress has been linked to numerous other health problems, increasing the overall subjective and psychological wellbeing of teachers may prevent associated health conditions and have positive secondary outcomes such as a reduction in sick absenteeism and an improvement in teaching outcomes. Interventions targeted at changing environmental factors, such as reducing work pressure, restructuring work content and improving communication, amongst others, are also considered to be important in sustainable health promotion interventions such as stress management (Bartholomew, Parcel, Kok, Gottlieb \& Fernandez, 2011). To this end, this study suggests that addressing environmental issues related to role problems, such as role conflict and role ambiguity, can have a significant impact on stress prevention or reduction amongst teachers.

\section{Limitations of the study}

The limitations of the study are mainly related to the measurement of concepts with reduced item scales for psychological wellbeing, leading to some of these scales being less reliable. The end result was the measure of psychological wellbeing as a global measure instead of measuring each of the six dimensions suggested by Ryff (1989a \& 1989b). Also, the fact that this was a cross-sectional study is a limitation. A standard limitation of cross-sectional studies is that they do not determine causality. Therefore, given the findings and methodology of this study, an opportunity has been created for the conduct of research in two broad areas. Further investigation of the direction and mechanisms of causality between correlated variables identified in this study would provide new information.

The knowledge generated by this study provides information for development and evaluation of a planned and systematic intervention, which focuses on changing specific variables such as role problems, negative affect and psychological wellbeing (Bartholomew et al., 2011). Such health promotion interventions can target these determinants in an attempt to improve teacher performance outcomes, which is a key goal for the Department of Education.

\section{Conclusion}

This study has provided insight into the application of theory to stress experienced by public school teachers in the Eastern Cape. It showed that the major contributors to teacher stress comprised environmental factors related to role problems, as well as personal factors, most important of which were psychological wellbeing and negative affect. The practical implications of the article provide a starting point for further research and the development of future interventions.

\section{Acknowledgements Competing interests}

The authors declare that they have no financial or personal relationship(s) which may have inappropriately influenced them in writing this article. 


\section{Author contributions}

M.L.M.V. (University of Maastricht) is the first author of the article and it is based on his PhD research. R.A.C.R. (University of Maastricht) was the main supervisor of the study. He reviewed and approved all the various stages of the work. H.W. (University of Maastricht) and P.S.R. (Human Science Research Council) were second supervisors and were also involved in reviewing and approving the work. K.D. (University of South Africa) was fundamental in study design, development of tools and analysis strategy. She also reviewed the article. G.M. (University of Fort Hare) contributed in the early conceptualisation and planning of the study, selection and training of interviewers and reviewing the various drafts of the study.

\section{References}

Abbott, R.A., Ploubidis, G.B., Huppert, F.A., Kuh, D., Wadsworth, M.E.J., \& Croudece, T.J. (2006). Psychometric evaluations and predictive validity of Ryff's psychological wellbeing items in a UK birth cohort sample. Health and quality of life outcomes, 4, 76. http://dx.doi.org/10.1186/1477-7525-4-76

Bandura, A. (1997). Self-efficacy: The exercise of control. New York: Freeman.

Bartholomew, L.K., Parcel, G.S., Kok, G., Gottlieb, N.H., \& Fernandez, M.E. (2011). Planning health promotion programs. An intervention mapping approach. San Francisco: Jossey-Bass.

Björkquist, K., \& Österman, K. (1992). Work stress symptoms scale. Retrieved, from http://www.vasa.abo.fi/svf/up/Scales/WSSS-English.pdf

Borg, M.G., \& Riding, R.J. (1991). Occupational stress and satisfaction in teaching. British Educational Research Journal, 17, 263-281. http://dx.doi.org/10.1080/ 0141192910170306

Bowers, T. (2001). Teacher absenteeism and ill health retirement: A review. Cambridge Journal of Education, 31(2), 135-157. http://dx.doi.org/10.1080/030576401200 6119

Byrne, B.M. (1999). The nomological network of teacher burnout: A literature review and empirically validated model. In R. Vandenberghe, \& A.M. Huberman (Eds.), Understanding and preventing teacher burnout: A sourcebook of international research practice (pp. 15-37). Cambridge: Cambridge University Press. http:// dx.doi.org/10.1017/CBO9780511527784.003

Caplan, R.D. (1987). Person-environment fit theory and organisations: Commensurate dimensions, time perspectives and mechanisms. Journal of Vocational Behaviour, $31,248-267$.

Caplan, R.D., \& Harrison, R.V. (1993). Person-environment fit theory: Some history recent developments, and future directions. Journal of Social Issues, 49, 253-275.

Chaplain, R. (1995). Stress and job satisfaction: A study of English primary school teachers. Educational Psychology, 15(4), 473-489.

Chida, Y., \& Steptoe, A. (2008). Positive psychological wellbeing and mortality: A quantitative review of prospective observation studies. Psychosomatic medicine, 70, 741-756

Dalgard, O.S., Mykletum, A., Rognerud, M., Johansen, R., \& Zahl, P.H. (2007). Education, sense of mastery and mental health: Results from a nationwide health monitoring study in Norway. BMC Psychiatry, 7(20), 9 pp. http://dx.doi.org/10.1186/147.244x-7-20

Diener, E. (2000). Subjective wellbeing: The science of happiness, and a proposal for national index. American Psychologist, 55, 34-43.

Diener, E., Suh, E., Lucas, R., \& Smith, H.L. (1999). Subjective wellbeing: Three decades of progress. Psychological Bulletin, 125, 276-302.

Dorman, J. (2003). Testing a model for teacher burnout. Australian Journal of Educational and Developmental Psychology, 3, 35-47.

Fejgin, N., Ephraty, N., \& Ben-Sira, D. (1995). Work environment and burnout of physical education teachers. Journal of Teaching in Physical Education, 15, 64-78.

Fredrickson, B.L. (1998). What good are positive emotions? A Review of General Psychology, 2, 300-319. http://dx.doi.org/10.1037/1089-2680.2.3.300, PMid:21850154

Fredrickson, B.L., \& Losada, M.F. (2005). Positive affect and the complex dynamics of human flourishing. American Psychologist, 607, 678-686. http://dx.doi.org/10.1037/ 0003-066X.60.7.678, PMid:16221001

French, J.R.P., Caplan, R.D., \& Harrison, R.V. (1982). The mechanisms of job stress and strain. London: Wiley.

Grandey, A.A., \& Cropanzano, R. (1999). The conservation of resources model applied to work-family conflict and strain. Journal of Vocational Behavior, 54, 350-370. http://dx.doi.org/10.1006/jvbe.1998.1666

Hall, E., Altman, M., Nkomo, M., Peltzer, K., \& Zuma, K. (2005). Potential attrition in education: The impact of job satisfaction, morale, workload and HIV/AIDS. Pretoria: HSRC Press.
Harrison, R.V. (1985). The person-environment fit model and the study of job stress. In T.A. Beehr, \& R.S. Bhagat (Eds.), Human stress and cognition in organizations (pp. 23-55). New York: Wiley.

Hobfoll, S.E., Freedy, J., Schaufeli, W.B., Maslach, C., \& Marek, T. (1993). Conservation of resources: A general stress theory applied to burnout. Philadelphia: Taylor \& Francis.

Jackson, L., \& Rothmann, S. (2006). Occupational stress, organizational commitment, and ill health of educators in the North West Province. South African Journal of Education, 26, 75-95.

Keyes, C.L.M. (2002). Selecting outcomes for the sociology of mental health: Issues of measurement and dimensionality. Journal of Health and Social Behaviour, 43(2), 207-222.

Keyes, C.L.M., \& Lopez, S.J. (2002). Toward a science of mental health: Positive directions in diagnosis and interventions. In C.R. Snyder, \& S.J. Lopez (Eds.), The handbook of positive psychology (pp. 45-59). New York: Oxford University Press.

Kyriacou, C. (1987). Teacher stress and burnout: An international review. Educationa Research, 29(2), 146-152. http://dx.doi.org/10.1080/0013188870290207

Kyriacou, C., \& Sutcliffe, J. (1978). A model of teacher stress. Educational Studies, 4, 1-6. http://dx.doi.org/10.1080/0305569780040101

Kyriacou, C., \& Sutcliffe, J. (1979). Teacher stress and satisfaction. Educational Research, 21(2), 89-96. http://dx.doi.org/10.1080/0013188790210202

Laughlin, A. (1984). Teacher stress in an Australian setting: Role of biographical mediators. Educational Studies, 10, 7-22. http://dx.doi.org/10.1080/0305569840100102

Lazarus, R.S. (1993). Coping theory and research: Past, present, and future. Psychosomatic Medicine, 55, 234-247. PMid:8346332

Lazarus, R.S., \& Folkman, S. (1984). Stress, appraisal, and coping. New York: Springer.

Manthei, R., \& Gilmore, A. (1996). Teacher Stress in Intermediate Schools. Educational Research, 38(1), 3-19.

Pines, A.M., \& Keinan, G. (2005). Stress and burnout: The significant difference. Personality and Individual Differences, 39, 625-635. http://dx.doi.org/10.1016/j. paid.2005.02.009

Rabin, S., Shorer, Y., Nadav, M., Guez, J., Hertzanu, M.S.W., \& Shiber, A. (2011) Burnout among general hospital mental health professionals and the salutogenic approach. Israeli Journal of Psychiatry Related Sciences, 48(3), 175-181.

Raschke, D.B., Dedrick, C.V., Strath, M.I., \& Hawkes, R.R. (1985). Teacher stress: The elementary teacher's perspective. Elementary School Journal, 85, 559-564. http:// dx.doi.org/10.1086/461421

Rodriguez, T.J. (2011). Psychological wellbeing and coping mechanisms of battered women. Asian Journal of Health Social Descriptive Section, 1, 111-127.

Rotter, J.B. (1966). Generalized expectancies for internal versus external control of reinforcement. Psychological Monographs: General and Applied, 80(1), 1-28.

Ryff, C.D. (1989a). Beyond Ponce De Leon and life satisfaction: New directions in the quest of successful aging. International Journal of Development, 12, 35-55.

Ryff, C.D. (1989b). Happiness is everything, or is it? Explorations on the meaning of psychological wellbeing. Journal of Personality and Social Psychology, 57, 1069-1081. psychological wellbeing. Journal of Personality and
http://dx.doi.org/10.1037/0022-3514.57.6.1069

Salami, S.O. (2010). Job stress and counterproductive work behaviour: Negative affectivity as a moderator. The Social Sciences, 5(6), 486-492. http://dx.doi.org/10.3923/ sscience.2010.486.492

Santavirta, N., Soloviena, S., \& Theorell, T. (2007). The association between job strain and emotional exhaustion in a cohort of 1028 Finnish teachers. British Journal of Education Psychology, 77, 213-228. http://dx.doi.org/10.1348/000709905X92045, PMid:17411496

Smith, M., \& Bourke, S. (1992). Teacher stress: Examining a model based on context workload, and satisfaction. Teaching and Teacher Education, 8, 31-46. http://dx.doi. org/10.1016/0742-051X(92)90038-5

SPSS version 17.0 [computer software] (2008). Chicago, SPSS, Inc.

Stansfeld, S.A., Fuhrer, R., Head, J., Ferrie, J., \& Shipley, M. (1997). Work and psychiatric disorder in the Whitehall II study. Journal of Psychosomatic Research, 43, 73-81. disorder in the Whitehall Il study. Journal of Psychos
http://dx.doi.org/10.1016/S0022-3999(97)00001-9

Statistics South Africa (2009). Community surveys 2007. Basic results - Eastern Cape. Retrieved September 12, 2009, from http://www.statssa.gov.za/Publications/ Report-03-01-32/Report-03-01-322007.pdf

Tennant, C. (2001). Work related stress and depressive disorders. Journal of Psychosomatic Research, 51, 697-704. http://dx.doi.org/10.1016/S0022-3999(01)00255-0

Tschannen-Moran, M., Woolfolk Hoy, A., \& Hoy, W.K. (1998). Teacher efficacy: Its meaning and measure. Review of Educational Research, 68(2), 202-248. http:// dx.doi.org/10.3102/00346543068002202

Van Bijl, H., \& Oosthuizen, P. (2007). Anxiety, depression, health attitudes and coping strategies in doctors and teachers in a Cape Town setting. South African Journal of strategies in doctors and teac
Psychiatry, June 1, 46-51.

Vazi, M.L.M., Ruiter, R.A.C., Van den Borne, B., Martin, G.M., Dumont, K., \& Reddy, P.S. (2011). Indicators of subjective and psychological wellbeing as correlates of teacher burnout in the Eastern Cape public schools, South Africa. International teacher burnout in the Eastern Cape public schools, South Africa. International
Journal of Education Administration Research and Policy Studies, 3(10), 160-169.

Watson, D., Clark, L.A., \& Tellegen, A. (1988). Development and validation of brief measures of positive and negative affect: The PANAS Scales. Journal of Personality and Social Psychology, 47, 1063-1070. http://dx.doi.org/10.1037/0022-3514.54.6.1063

Yu, K.Y.T. (2009). Affective influences in person-environment fit theory: Exploring the role of affect as both cause and outcome of P-E fit. Journal of Applied Psychology, 94(5), 1210-1226. http://dx.doi.org/10.1037/a0016403, PMid:19702366 